University of Nebraska - Lincoln

DigitalCommons@University of Nebraska - Lincoln

$11-1-2004$

\title{
Children's Perceptions of Family Relationships as Assessed in a Doll Story Completion Task: Links to Parenting, Social Competence, and Externalizing Behavior
}

\author{
Deborah Laible \\ Southern Methodist University, del205@lehigh.edu \\ Gustavo Carlo \\ University of Nebraska-Lincoln, carlog@missouri.edu \\ Julia C. Torquati \\ University of Nebraska-Lincoln, jtorquati1@unl.edu \\ Lenna Ontai \\ University of Nebraska-Lincoln
}

Follow this and additional works at: https://digitalcommons.unl.edu/psychfacpub

Part of the Psychiatry and Psychology Commons

Laible, Deborah; Carlo, Gustavo; Torquati, Julia C.; and Ontai, Lenna, "Children's Perceptions of Family Relationships as Assessed in a Doll Story Completion Task: Links to Parenting, Social Competence, and Externalizing Behavior" (2004). Faculty Publications, Department of Psychology. 35.

https://digitalcommons.unl.edu/psychfacpub/35

This Article is brought to you for free and open access by the Psychology, Department of at DigitalCommons@University of Nebraska - Lincoln. It has been accepted for inclusion in Faculty Publications, Department of Psychology by an authorized administrator of DigitalCommons@University of Nebraska - Lincoln. 


\title{
Children's Perceptions of Family Relationships as Assessed in a Doll Story Completion Task: Links to Parenting, Social Competence, and Externalizing Behavior
}

\author{
Deborah Laible, Southern Methodist University \\ Gustavo Carlo, Julia Torquati, and Lenna Ontai, University of Nebraska-Lincoln
}

\begin{abstract}
This study was designed to examine the links between parenting, children's perceptions of family relationships, and children's social behavior. Seventy-four children $(\mathrm{M}$ age $=6.01$ years; 39 boys; 35 girls $)$ and their parents took part in the study. Children completed relationship-oriented doll stories that were coded for coherence, prosocial themes, and aggressive themes. Parents completed a report of their child's social behavior, a parenting scale, and a number of demographic items. Teachers also completed measures of children's social competence and externalizing behavior. Warm parenting predicted both a child's representation of prosocial themes in the doll stories and social competence, whereas harsh parenting predicted both a child's use of aggressive themes in the doll stories and a child's externalizing behavior. These findings support the idea that children are constructing models of relationships out of the early interactions with caregivers, and that they use these representations to guide their social behavior.
\end{abstract}

Keywords: representations of relationships; social competence; parenting; externalizing behavior

Recently, researchers have linked children's narrative responses in doll story dilemmas to aspects of parenting and social behavior. The preliminary work that has been done supports the idea that children's responses to these doll story measures might tap both their emotion regulation skills and their representations of family relationships, and that these skills relate to children's peer relationships (e.g. Page \& Bretherton, 1991; Solomon, George \& De Jong, 1995). Despite this, empirical work on children's representations of relationships (as assessed in doll story narratives) is still in its infancy. Thus, the goal of the current study was to expand on this growing area of literature by examining whether parenting style related to a child's representations of relationships and whether these representations mediated the link between parenting and social competence.

Correspondence should be addressed to Deborah Laible, Department of Psychology, Southern Methodist University, Dallas, TX 75275-0442, USA. Email: dlaible@mail.smu.edu

Published in Social Development 13:4 (November 2004), pp. 551-569. Copyright (C) 2004 Blackwell Publishing Ltd. Used by permission. "The definitive version is available at www.blackwell-synergy.com." 
A child's earliest experience with relationships occurs in the context of the family, and as a result, the family plays an influential role in the child's development of social understanding. Because family life offers rich avenues for social experiences, it is logical to expect that relationships with parents and siblings are influential in a child's development of social understanding. A child's daily interactions with parents - including conflict, shared pretend play, humor, emotional management, discussions about a child's behavior-provide a natural laboratory in which a child constructs representations of her social world and of the people in her social world (Thompson, 1998).

Attachment theorists have long stressed the idea that children learn about themselves, others, and relationships in the context of the attachment relationship with parents. Attachment theorists have stressed (Bowlby, 1980; Bretherton, 1993) that young children construct 'internal working models' out of early relationships with caregivers. These internal working models are representations of the self, attachment figures, and relationships, and have been conceptualized as affective-cognitive filters that influence the way in which children respond to social partners and the way in which they view themselves in the social world (Bretherton, 1990). Thus, if a caregiver has been sensitive to a child's needs (including respecting her need for autonomous exploration), a child will construct an internal working model of herself as lovable and self-reliant, and will respond to other social partners with warmth and affection. Conversely, if an attachment figure has repeatedly been insensitive to a child's needs for comfort and exploration, the child will construct an internal working model of the self as unlovable and not self-reliant, and will respond to a partner in an ambivalent or rejecting manner.

Research supporting the existence of internal working models is in its infancy. The vast majority of attachment theorists have argued for the existence of internal working models because of the empirical links between attachment security and a child's other social relationships (e.g., peer interactions) and a child's sense of self. Empirical evidence supports relations between attachment security and both aspects of the self (e.g., self-esteem) and social competence (Cassidy, 1998; Kerns, 1994; Sroufe, 1983). Despite these studies, the research has not always been consistent with regard to links between attachment security and peer interactions; while some studies reveal that children with secure attachment histories are more competent with peers, others have not found such relations particularly with unfamiliar peers (see Thompson, 1998, for a review). Thus, overall, although the pattern of research findings supports the existence of internal working models, the inconsistency of the findings in some areas of research raises the possibility that internal working models are likely influenced by a multitude of significant relationships that a child has (including relationships with peers, siblings, and other adults) and that these models may not always be immediately transferred to novel relationships (e.g., with unfamiliar peers).

Theorists outside of the attachment field have argued that young children's understanding of the social world is primarily organized in scripts (Nelson, 1981), and that children use these scripts (constructed out of family interactions) to understand the intentions of others and to guide their behavior in social experiences. Scripts are mental representations (as are working models) that organize experience about predictable actions and roles that comprise events (Hudson, 1993) and derived from real-world experiences. These scripts are believed to be accessible both through the behavior that they guide and through children's language (Woolgar, 1999). Researchers have attempted to access these scripts primarily through children's storytelling and narrative responses (e.g., Oppenheim, Emde \& 
Warren, 1997), and links between these scripts (as assessed through narratives) and children's behavior have been shown (Weidman \& Strayhorn, 1992; see also Woolgar, 1999 for a review).

Recently, researchers have attempted to access young children's social scripts and understanding of relationships through the use of doll story stems (e.g., MacArthur Story Stem Battery, Attachment Doll Story Completion Task, and Manchester Child Attachment Story Task) (see Bretherton, Prentiss \& Ridgeway, 1990; Green, Stanley, Smith \& Goldwyn, 2000; Solomon et al., 1995; Oppenheim et al., 1997). These techniques involve the use of vivid story stems (enacted with small dolls) that are designed to evoke narrative responses from children. Each story stem presents the child with a complex (and often conflictual) relationship-oriented story that leaves the child to finish the story at the 'high point' and provide a resolution to the conflict. The story stems act as a catalyst to provoke children to draw upon their scripted knowledge of relationships (and social understanding) to resolve the conflict (and to organize the child's feelings into coherent narratives) (Robinson, Herot, Haynes \& Mantz-Simmons, 2000). Story stem methodologies are expected not only to elicit a child's scripts for responding to social dilemmas and his/her understanding of family relationships and parenting, but also to challenge a child's ability to regulate emotions (Oppenheim et al., 1997).

Researchers have found empirical evidence that these narrative doll story measures do in fact assess a child's social scripts; they have found fairly consistent relations between children's responses to relationship-oriented story stems and aspects of children's social behaviors (George et al., 1995; Oppenheim et al., 1997; Page \& Bretherton, 2001; Warren, Oppenheim \& Emde, 1996). For example, Warren and her colleagues (1996) found associations between children's production of destructive themes in narratives and teacher reports of externalizing behavior. Children who portrayed more violent and destructive themes in their narrative responses to relationship-oriented doll story stems were rated by teachers as having more externalizing behavioral problems than those who did not. In the same sample of children, Oppenheim et al. (1997) found that children who portrayed caregivers in the doll story stems as being negative (i.e., physically or verbally abusive) were also more likely to be rated as having behavioral problems by mothers. Similarly, in a study of 6-year-old children, Solomon et al. (1995) found that children with controlling attachments not only produced more frightening themes in attachment doll stories, but were also rated by parents and teachers as displaying more aggressive behavior towards peers.

Research (Bretherton et al., 1990; Cassidy, 1988) has also linked children's responses to doll story completions with measures of children's attachment security (although these findings have not been as conclusive as the findings linking children's narratives to aspects of social behavior). Children's use of coherent discourse and their positive representations of attachment figures in these narrative assessments have generally predicted children's attachment behavior in laboratory assessments (George \& Solomon, 1994; Kaplan, 1987; Turner, 1991), but these findings are weak and have not always been found by researchers using other assessments of attachment (e.g. Bretherton et al., 1990; Oppenheim, 1997). Overall, research suggests that such narrative assessments capture some dimensions of attachment security, but may not be particularly useful for discriminating between avoidant and resistant attachments (Bretherton et al., 1990; Solomon \& George, 1999). Nonetheless, narrative assessments remain a popular, albeit controversial, way to 
assess attachment patterns (see, e.g., a newly developed measure, The Manchester Child Attachment Story Task (Green et al., 2000)).

Several aspects of sensitive parenting, however, have been linked with children's representations of relationships in these narrative assessments. For example, Oppenheim and colleagues (Oppenheim et al., 1997; Oppenheim, Emde \& Wamboldt, 1996) have linked maternal and paternal co-constructions with a child's representations of prosocial and antisocial themes in the MacArthur Story Stem Battery. Children whose parents who were rated by observers as providing more sensitive guidance and shared construction when constructing a story from a wordless storybook produced more coherent and prosocial narratives in the MacArthur Story Stem Battery than did children whose parents received lower ratings. Similarly, Laible and Thompson (2002) found that mothers who were more likely to resolve and compromise in conflict when the child was 30 months of age had children who six months later produced more coherent and prosocial narratives in a shortened version of the MacArthur Story Stem Battery.

\section{The Current Study}

In conclusion, there is accumulating evidence that children's responses to these relationship-oriented doll story completion tasks are related not only to their social understanding and understanding of relationships, but also to their real-life experiences within families. Clearly, however, this work is in its preliminary stages, and more work is needed to continue to examine the links between children's responses to such narrative measures, their social behaviors, and their experiences within the family.

In this study, we examined three new issues related to this line of inquiry. The first question that we were interested in examining was whether parenting styles predicted children's representations of family relationships (as assessed in a doll story completion task). Although (as discussed above) there has been some preliminary work linking particular aspects of parenting (e.g., conflict resolution) to children's perceptions of relationships in these narrative measures, we were not able to locate any work linking more global aspects of parenting styles to the themes children were producing in these narrative measures. In fact, Oppenheim et al.'s (1997) study of children's representations of relationships called for more studies that examine the links between children's representations and their actual experiences with parenting.

The second question that we were interested in was whether these representations of relationships (as assessed in the attachment doll stories) predicted children's social competence. Although previous work has consistently linked children's aggressive themes in narrative assessments with externalizing behavior (and we too examined this issue), fewer researchers have linked children's perceptions of family relationships (in narrative assessments) with children's social competence per se.

Finally, we were also interested in examining whether children's representations of relationships mediated the relationship between parenting and social competence as predicted by attachment researchers. Researchers have found fairly consistent evidence linking parenting styles to a child's social behavior. Warm, supportive parenting has been linked with a variety of positive social behaviors including high levels of prosocial behavior and social competence (Eisenberg \& Fabes, 1998; Maccoby \& Martin, 1983). In contrast, harsh parenting has been linked with a variety of antisocial outcomes and externalizing 
problems (Coie \& Dodge, 1998; Patterson, 1986). Despite this, however, the mechanisms responsible for this relationship are not clear and it certainly seems plausible that representations of relationships might be one possible mechanism through which parenting exerts its influence.

In this study, we used Bretherton et al.'s (1990) Attachment Doll Story Completion Task (ADSCT) because of its focus on attachment and other aspects of parent-child relationship issues. Rather than using a categorical approach to classifying children as secure or insecure on the basis of their responses to the ADSCT, children's responses to the ADSCT were coded for a number of prosocial and aggressive content themes and coherence. More recent use of narrative measures like the ADSCT and the MacArthur Story Stem Battery have used such a thematic approach (Laible \& Thompson, 2002; Oppenheim et al., 1997; Page \& Bretherton, 2001; Toth, Cicchetti, MacFie \& Emde, 1997; Warren et al., 1996). A thematic approach has the statistical advantage of having continuous rather than categorical variables. In addition, substantial controversy exists as to whether attachment patterns are in fact assessed in children's responses to the ADSCT (see, e.g., Thompson, 1998). Finally, coherence during the doll story task was also assessed because the ability to construct emotionally open and coherent narratives is believed to reflect the underlying consistency and accessibility of representations and to be related to aspects of parenting and social behavior (Bretherton, 1990).

Based on the previous empirical work and theory, we expected to find that warm parenting predicted a child's prosocial themes and his/her ability to speak coherently about those relationships (in the doll story completion task). In contrast, we expected harsh parenting to be related to more aggressive perceptions of relationships. Finally, we also expected that these representations of relationships would also contribute to predicting social competence (and lack of externalizing behavior). In addition, we expected representations of relationships to partially mediate the relationship between parenting dimensions and social behavior.

\section{Method}

\section{Participants}

Participants consisted of 74 children from preschool through second grade ( 25 preschool children, 14 kindergarten children, 16 first-grade children, 17 second-grade). Participants were about equally split by gender ( 39 boys, 35 girls) and had a mean age of 6.02 years $(\mathrm{SD}=1.18$, range 4.0 years-8.25 years). Preschool participants were recruited through a university preschool program. All other participants were recruited through after-school programs. Most of the participants lived with both biological parents (78\%) and were from primarily Caucasian families (76\%). Each family who participated in the study received $\$ 10$.

\section{Procedure}

Children and their parents were brought into a laboratory playroom. Parents were asked to complete a report of their child's social behavior (Social Competence and Behavior Evaluation (SCBE)), a parenting scale, and a number of demographic items outside the playroom while their children participated in the doll story interviews. Children's completions of the doll story narratives were video recorded, and eventually transcribed verbatim and coded for prosocial and aggressive themes and coherence. Teachers of 
the children were also contacted and asked to complete the measure of the children's social behavior (SCBE).

\section{Measures}

Parenting. Mothers completed the Parent Perception Inventory (PPI) (Hazzard, Christensen \& Margolin, 1983). The PPI consists of 20 items and two subscales: warm and harsh parenting. These dimensions of parenting have been used in previous research (Leve \& Fagot, 1997; Wagner, Cohen \& Brook, 1996) and have the advantage of keeping the interpretation of results relatively straightforward (i.e., by being able to link representations of relationships to a single dimension of parenting (e.g. warmth) rather than warmth and control). The PPI is rated on a five-point scale (from never to a lot) and was designed for use with young children. The PPI has been used with parents of young children (see, e.g., Hilton \& Devall, 1998; McCloskey, Figueredo \& Koss, 1995) and is believed to reflect the underlying emotional climate in the home. In addition, the scale has shown both convergent and predictive validity and has been found to be significantly correlated with child reports of parental behavior (Glaser, Horne \& Myers, 1995; McCloskey et al., 1995). The scales had adequate internal consistency ( $\alpha=.76$ for warm parenting, $\alpha=.74$ for harsh parenting). A sample item from the warm parenting scale was 'How often do you talk to your child, just listen, or have a good conversation with him or her?' and a sample item from the harsh parenting scale was 'How often do you spank, slap, or hit your child?'

Social Competence. Both teachers and mothers completed the Social Competence and Behavior Evaluation (SCBE) (LaFreniere, 1995). The SCBE is a 79-item scale rated from 1 'never' to 6 'always' that assesses a child's social competence, externalizing behaviors, and internalizing behaviors. Due to the young children in the study, we focused on only two of the subscales reflecting overt social behaviors (social competence and externalizing behavior), because internalizing behaviors are not always obvious in young children (e.g., 'worries'). This scale (and a shortened version of this scale) have shown to be psychometrically sound with young children (Dumas, Martinez \& LaFreniere, 1998; LaFreniere \& Dumas, 1996). The social competence subscale assesses a child's level of secure (e.g., 'easily adjusts to new situations'), joyful (e.g., 'laughs easily'), calm (e.g., 'stays calm when there are conflicts in the group'), prosocial (e.g., 'cooperates with other children in group activities'), and autonomous (e.g., 'persistent in solving own problems') behavior with peers. The externalizing behavior subscale assesses the child's level of aggressive (e.g., 'bullies weaker children'), angry (e.g., 'gets angry when interrupted'), egoistic (e.g., 'has to be first'), and oppositional behavior (e.g., 'defiant when reprimanded'). Internal consistencies on the 46-item social competence scale and 16-item externalizing scale were adequate $(\alpha=.92$ and $\alpha=.85$ for parental report of social competence and externalizing behavior; $\alpha=.85$ and $\alpha=.79$ for teacher report of social competence and externalizing behavior).

Perceptions of Family Relationships. In order to assess perceptions of family relationships, children were administered Bretherton's Attachment Doll Story Completion Task (Bretherton et al., 1990). The attachment doll stories were designed to tap a child's ability to produce positive outcome narratives from complex, conflictual relationship-oriented story stems and are believed to assess a child's representations of relationships (Bretherton, 1990). Such skills have been linked to a wide variety of positive developmental out- 
comes, including emotional regulation, the ability to share personal experiences, and fewer behavioral problems (Oppenheim et al., 1997a, 1997b).

The researcher explained to the child that for this game, she would make up some stories with the dolls and that for each story the researcher would start the story and the child could finish it. Following this, a warm-up story was presented using the dolls, and the child was encouraged to manipulate the dolls. The stems were presented in a spirited, dramatic manner and all ended with the request, 'Can you show me what happens next?' Nondirective prompts, for example, 'Does anything else happen?' were used to assist the child's narrative. The experimenter moved to the next story stem after the child had addressed the main issue in the stem or had indicated that he or she was finished with the story. In total, there were six stories that included a story about spilled juice, a hurt knee, a monster in the bedroom, and a separation and reunion. A sample story (taken from Bretherton et al., 1990) is:

'Here is our family eating dinner and Bob/Jane gets up and reaches and spills his/her juice.'

Mother doll: 'Bob/Jane you spilled your juice!'

'Show me what happens now.'

Children's responses to the doll stories were transcribed verbatim from the videotapes and a second researcher checked the transcripts for accuracy. Any actions that children made with the dolls were also summarized in the transcripts (e.g., two dolls embracing). Children's narrative transcripts were coded using an adapted coding system developed by the MacArthur Narrative Workgroup (see Oppenheim et al., 1997) for use with similar doll story stems. Two independent coders coded 20 common transcripts to establish reliability of coding. Percent agreement between the two coders and the mean number of coded themes per transcript appear in parentheses. Each theme was treated as a category and Cohen's kappa for the coded content themes across narratives was .83. Overall content themes were as follows:

1. personal injury $(88 \%, \mathrm{M}=.34, \mathrm{SD}=.53)$ : a character was physically injured or hurt, and the focus was on the injury and not on the aggression;

2. aggression $(90 \%, \mathrm{M}=.36, \mathrm{SD}=.91)$ : a character made hostile or destructive gestures;

3 . punishment $(91 \%, \mathrm{M}=.44, \mathrm{SD}=.64)$ : a character was portrayed as punishing another (by spanking or time out).

4. affection $(80 \%, \mathrm{M}=.62, \mathrm{SD}=.63)$ : a character was displayed as hugging, kissing, being praised, etc.;

5. affiliation $(83 \%, \mathrm{M}=.56, \mathrm{SD}=.81)$ : characters participated in a positive activity together;

6. empathy/helping $(85 \%, \mathrm{M}=1.33, \mathrm{SD}=.89)$ : a character or the child identified with or demonstrated an understanding of the thoughts and feeling of another or helped another with a task;

7. reparation/guilt $(88 \%, \mathrm{M}=.48, \mathrm{SD}=.52)$ : a character made amends or displayed feelings of guilt;

8. atypical negative responses $(80 \%, \mathrm{M}=1.00, \mathrm{SD}=1.21)$ : the child displayed disorganized or very unusual responses with a clear negative tone. 
Because children often presented more than one theme sequentially in narrative, a narrative could receive more than one coded content theme. Content themes in each category were summed across all the narratives, and in order to reduce the number of content themes, based on conceptual similarity, two composite content themes were formed by summing themes (following Oppenheim et al., 1997): (a) a prosocial composite (including empathy/helping, reparation/guilt, affiliation, affection), and (b) an aggressive composite (including aggression, punishment, personal injury, and atypical negative responses).

In addition to content themes, the narratives were coded for coherence (again following Oppenheim et al., 1997) on a 10-point scale. The odd-numbered anchor points were as follows: 1 (fragmented, shifted story line), 3 (child understood conflict, but did not offer resolution and part of the story was incoherent), 5 (child understood the conflict and handled it by using simplification of the story), 7 (child understood the story and offered resolution, but the story was short with no embellishment), 9 (child understood conflict, offered embellished resolution; there were no incoherent segments) (Oppenheim et al., 1997). A composite score of narrative coherence was formed by averaging the scores across narratives. Internal consistency (Cronbach's a) for the measure was .82 and interrater reliability using interclass correlations ranged from .72 to .89 .

\section{Results}

\section{Descriptive and Bivariate Data}

The descriptive data on both the doll story themes, parenting, and social competence all appear in Table 1. In addition, bivariate correlations among the variables appear in Table 2. Consistent with our hypotheses, children's representations of relationships were correlated with parenting styles. Parents who reported using warm parenting techniques had children who produced more prosocial resolutions to the doll stories than those who did not. Parents reporting harsh parenting techniques had children who produced fewer prosocial themes and more aggressive themes.

Children's representations of relationships in the doll stories were also related to both teachers and parents' reports of social behavior. Children who represented relationships as prosocial in ADSCT were rated by teachers as having fewer externalizing problems and by parents as being more socially competent. In contrast, children with aggressive repre-

Table 1. Descriptive Data

\begin{tabular}{lccc}
\hline Variable & Mean & SD & Range \\
\hline Warm Parenting & 3.76 & .35 & $2.8-4.5$ \\
Harsh Parenting & 2.89 & .41 & $1.8-4.3$ \\
Aggressive Narratives & 2.62 & 2.46 & $0-9$ \\
Prosocial Narratives & 3.04 & 1.74 & $0-7$ \\
Coherence in Narratives & 5.18 & 1.66 & $1.22-7.80$ \\
Teacher Report of Social Competence & 2.93 & .79 & $1.33-4.38$ \\
Teacher Report of Externalizing Behavior & 1.34 & .96 & $.65-4.95$ \\
Parent Report of Social Competence & 3.16 & .53 & $1.62-4.31$ \\
Parent Report of Externalizing Behavior & 1.66 & .61 & $1.38-4.56$ \\
\hline
\end{tabular}




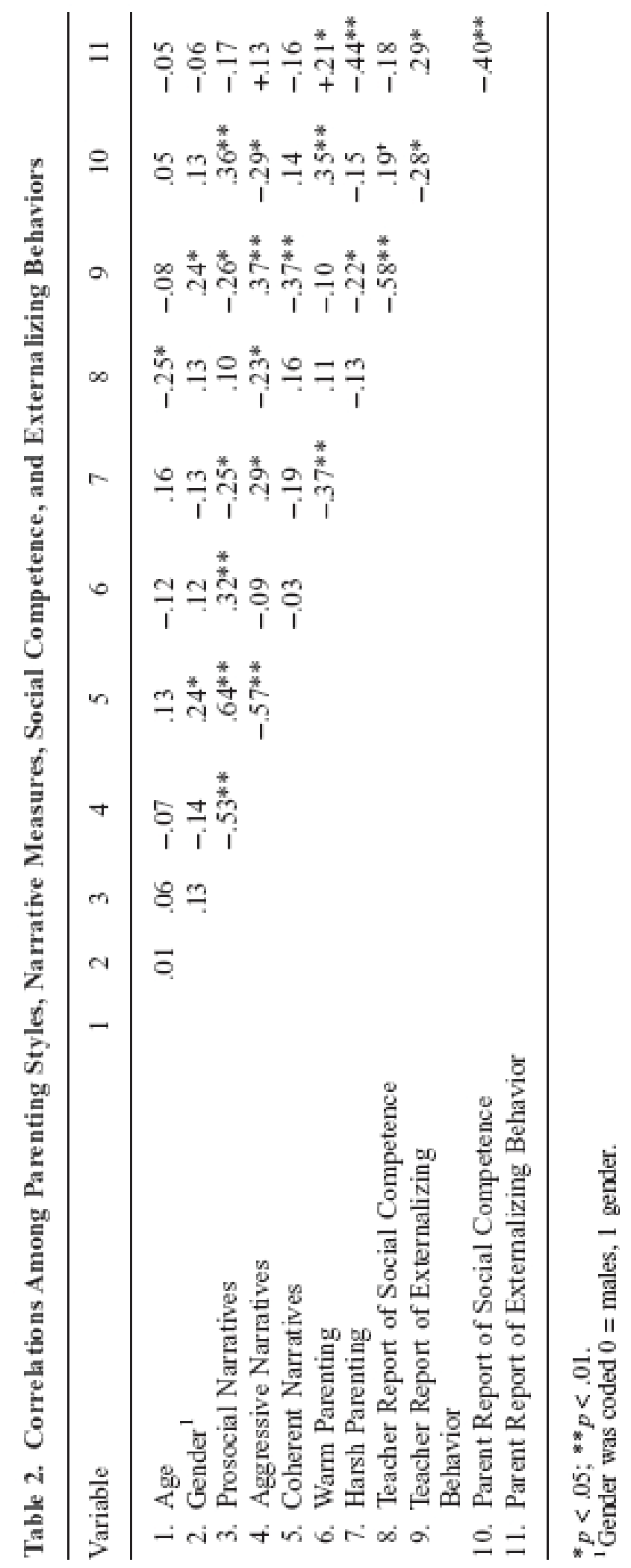


sentations of relationships in ADSCT were rated as less socially competent by both parents and teachers and as more externalizing by teachers only than children who did not. Finally, coherence during story completions was also related to teacher reports of externalizing behaviors (but not to social competence as predicted). Children who told more coherent narratives in the doll stories were also rated by teachers as less externalizing.

Warm parenting was also related to children's social behavior, but contrary to prediction only to parental reports of social behavior. Mothers who reported using warm parenting techniques with children also reported that their children were socially competent and had few externalizing problems. Harsh parenting was also related to teacher reports of externalizing, but contrary to prediction was unrelated to social competence or to parent reports of externalizing. Children whose parents reported harsh parenting styles were rated by teachers as displaying more externalizing behavior.

\section{Regression Models Predicting Perceptions of Family Relationships}

In order to predict children's prosocial and aggressive representations of family relationships (and narrative coherence) in the doll stories, hierarchical regression models were built (see Table 3). Age (in months) and gender were entered on the first step of all regression models to control for their main effects. Previous researchers have found differences in children's narratives on the basis of both age and gender (Laible \& Thompson, 2002; Oppenheim et al., 1997) (with girls and older children typically producing the most coherent and prosocial narratives).

In the model predicting prosocial representations of relationships, the entrance of the control variables (age and gender) on the first step of the model failed to significantly increase the amount of systematic variance accounted for by the model. The addition of the parenting variables on the second step, however, did increase the amount of systematic variance accounted for by the model and led to a significant overall predictive model. Only warm parenting, however, made a significant independent contribution to the model. Children whose parents reported using warm parenting techniques produced the most prosocial themes in the attachment doll stories.

In the model predicting aggressive representations of relationships, the addition of the control variables (age and gender) on the first step of the model failed to significantly increase the amount of variance accounted for by the model. The addition of the parenting variables on the second step, however, did increase the amount of systematic variance accounted for by the model and led to a significant overall predictive model. Only harsh parenting made a significant independent contribution to the model with children whose parents reported harsh parenting techniques producing the most aggressive themes in the attachment doll stories.

In the model predicting a child's ability to coherently discuss relationships in the doll stories, the addition of age and gender on the first step of the model significantly increased the amount of systematic variance accounted for in the model. The addition of parenting variables on the second step of the model did not increase the amount of systematic amount variance in the model. Despite this, however, the full model was significant. Only gender made a significant independent contribution to the model. Girls produced more coherent narratives than did boys.

Regression Models Predicting Social Competence and Externalization Behavior

In order to determine whether children's representations of relationships predicted social 
Table 3. Regression Models Predicting Representations of Family Relationships in Doll Story Completion Task

Prosocial Themes:

\begin{tabular}{|c|c|c|c|c|}
\hline Predictor & $\beta$ at final step & $\mathrm{R}^{2}$ & $\mathrm{R}^{2}$ change & F change \\
\hline \multicolumn{5}{|l|}{ Step 1} \\
\hline Age & .14 & & & \\
\hline \multirow[t]{2}{*}{ Gender } & .11 & & & \\
\hline & & .03 & .03 & .97 \\
\hline \multicolumn{5}{|l|}{ Step 2} \\
\hline Warm Parenting & $.27^{*}$ & & & \\
\hline \multirow[t]{2}{*}{ Harsh Parenting } & -.20 & & & \\
\hline & & $.18^{*}$ & $.15^{* *}$ & $5.33^{* *}$ \\
\hline \multicolumn{5}{|l|}{ Aggressive Themes: } \\
\hline Predictor & $\beta$ at final step & $\mathrm{R}^{2}$ & $\mathrm{R}^{2}$ change & F change \\
\hline \multicolumn{5}{|l|}{ Step 1} \\
\hline Age & -.15 & & & \\
\hline \multirow[t]{2}{*}{ Gender } & -.15 & & & \\
\hline & & .04 & .04 & 1.30 \\
\hline \multicolumn{5}{|l|}{ Step 2} \\
\hline Warm Parenting & -.01 & & & \\
\hline \multirow[t]{2}{*}{ Harsh Parenting } & $.32 * *$ & & & \\
\hline & & $.14^{*}$ & $.10^{*}$ & $3.69^{*}$ \\
\hline \multicolumn{5}{|l|}{ Coherence: } \\
\hline Predictor & $\beta$ at final step & $\mathrm{R}^{2}$ & $\mathrm{R}^{2}$ change & F change \\
\hline \multicolumn{5}{|l|}{ Step 1} \\
\hline Age & .20 & & & \\
\hline \multirow[t]{2}{*}{ Gender } & $.25^{*}$ & & & \\
\hline & & $.09 *$ & $.09^{*}$ & $3.27^{*}$ \\
\hline \multicolumn{5}{|l|}{ Step 2} \\
\hline Warm Parenting & -.10 & & & \\
\hline \multirow[t]{2}{*}{ Harsh Parenting } & -.24 & & & \\
\hline & & $.14^{*}$ & .05 & 1.93 \\
\hline
\end{tabular}

${ }^{*} p<.05 ; * * p<.01$.

competence and externalizing behavior, hierarchical regression models were built (see Tables 4 and 5). Age and gender were entered as controls because previous research has indicated that age and gender are related to prosocial and antisocial behavior (Coie \& Dodge, 1998; Eisenberg \& Fabes, 1998). Parenting variables (warm and harsh parenting) were entered on the second step to assess whether or not they related to social behavior. Finally, representations of relationships were entered on the final step to see if they con- 


\section{Table 4. Regression Models Predicting Social Competence}

Teacher Report:

\begin{tabular}{|c|c|c|c|c|}
\hline Predictor & $\beta$ at final step & $\mathrm{R}^{2}$ & $\mathrm{R}^{2}$ change & F change \\
\hline \multicolumn{5}{|l|}{ Step 1} \\
\hline Age & $-.36^{* *}$ & & & \\
\hline Gender & .15 & $.15^{*}$ & $.15^{* *}$ & $5.03 * *$ \\
\hline \multicolumn{5}{|l|}{ Step 2} \\
\hline Warm Parenting & .09 & & & \\
\hline Harsh Parenting & .10 & $.16^{*}$ & .01 & .39 \\
\hline \multicolumn{5}{|l|}{ Step 3} \\
\hline $\begin{array}{l}\text { Positive Representations } \\
\text { of Relationships }{ }^{1}\end{array}$ & $.28^{*}$ & $.23^{*}$ & .06 & $4.48^{*}$ \\
\hline \multicolumn{5}{|l|}{ Parent Report: } \\
\hline Predictor & $\beta$ at final step & $\mathrm{R}^{2}$ & $\mathrm{R}^{2}$ change & F change \\
\hline \multicolumn{5}{|l|}{ Step 1} \\
\hline Age & -.01 & & & \\
\hline Gender & .03 & .01 & .01 & .64 \\
\hline \multicolumn{5}{|l|}{ Step 2} \\
\hline Warm Parenting & $.32^{* * *}$ & & & \\
\hline Harsh Parenting & .03 & $.16^{*}$ & $.15^{* *}$ & $5.30 * *$ \\
\hline \multicolumn{5}{|l|}{ Step 3} \\
\hline $\begin{array}{l}\text { Positive Representations } \\
\text { of Relationships }{ }^{1}\end{array}$ & $.28^{*}$ & $23^{* *}$ & $.07^{*}$ & $5.19^{*}$ \\
\hline
\end{tabular}

$* p<.05 ; * * p<.01$.

${ }^{1}$ This variable was the combined number of positive themes in the ADST minus the number of negative themes.

tributed anything above and beyond the parenting variables. Because both prosocial and aggressive representations of relationships were highly negatively correlated (and thus entering both into a model created problems with collinearity), a composite score (positive representations of relationships) was formed by subtracting the number of aggressive doll story themes from the positive themes.

In the model predicting teacher's report of social competence, the entrance of the control variables on the first step, but not the parenting variables on the second step increased significantly the amount of variance accounted for by the model. The addition of positive representations of relationships on the third step, however, increased significantly the variance accounted for by the model and led to a significant overall predictive model. Both age and positive representations of relationships made significant independent contributions to the model. Younger children and children who discussed positive representations of relationships in the ADST were rated by teachers as the most competent. 
Table 5. Regression Models Predicting Externalizing Behavior

Teacher Report:

\begin{tabular}{lcccc}
\hline Predictor & $\beta$ at final step & $\mathrm{R}^{2}$ & $\mathrm{R}^{2}$ change & $\mathrm{F}$ change \\
\hline $\begin{array}{l}\text { Step 1 } \\
\quad \text { Age }\end{array}$ & .16 & & & \\
$\quad$ Gender & $-.24^{* *}$ & $.14^{*}$ & $.14^{* *}$ & $4.77^{*}$ \\
$\begin{array}{l}\text { Step 2 } \\
\quad \text { Warm Parenting }\end{array}$ & .18 & & & \\
$\quad$ Harsh Parenting & .02 & $.16^{*}$ & .02 & .49 \\
$\begin{array}{l}\text { Step 3 } \\
\text { Positive Representations } \\
\quad \text { of Relationships }\end{array}$ & $-.39 * *$ & $.29^{* *}$ & $.13^{* *}$ & $9.59^{* *}$ \\
\hline
\end{tabular}

Parent Report:

\begin{tabular}{|c|c|c|c|c|}
\hline Predictor & $\beta$ at final step & $\mathrm{R}^{2}$ & $\mathrm{R}^{2}$ change & F change \\
\hline \multicolumn{5}{|l|}{ Step 1} \\
\hline Age & .03 & & & \\
\hline Gender & .21 & .02 & .02 & .49 \\
\hline \multicolumn{5}{|l|}{ Step 2} \\
\hline Warm Parenting & -.01 & & & \\
\hline Harsh Parenting & $.37^{* *}$ & $.19^{*}$ & $.17^{* *}$ & $6.17^{* *}$ \\
\hline \multicolumn{5}{|l|}{ Step 3} \\
\hline $\begin{array}{l}\text { Positive Representations } \\
\text { of Relationships }{ }^{1}\end{array}$ & -.13 & $.20^{*}$ & .01 & 33 \\
\hline
\end{tabular}

${ }^{*} p<.05 ; * * p<.01$.

${ }^{1}$ This variable was the combined number of positive themes in the ADST minus the number of negative themes.

In the model predicting parental report of social competence, the entrance of age and gender failed to significantly increase the amount of systematic variance in the model. Both the addition of the parenting variables on the second step and representations of relationships in the third step significantly increased the variance accounted for in the model. Both warm parenting and positive representations of relationships made significant independent contributions to the model. Parents who reported warm parenting practices rated children as more socially competent than those who did not. Also, children who produced more positive representations of relationships in the doll stories were rated by parents as being more socially competent than those who did not.

In the model predicting teacher reports of externalizing behavior, the entrance of the control variables on the first step of the model significantly increased the variance accounted by the model. The addition of the parenting variables on the second step of the model did not significantly increase the variance accounted for in the model, but the ad- 
dition of positive representations of relationships on the third step did. Both gender and representations of relationships made significant independent contributions to the model. Boys and children who produced fewer positive representations of relationships in the doll stories were most likely to be rated by teachers as having externalizing problems.

In the model predicting parental report of externalizing behavior, only the addition of the parenting variables on the second step of the model significantly increased the amount of variance accounted for in the model. In the final significant overall predictive model, only harsh parenting made a significant independent contribution to the model. Parents who reported using harsh parenting techniques were also more likely to report that their children displayed high levels of externalizing behavior.

Did Representations of Family Relationships Mediate the Relationship Between Parenting and Social Competence?

To test whether representations of family relationships mediated the relations between the parenting variables and social competence and externalizing behavior, three hierarchical regression models were built for each outcome variable (following Baron \& Kenny, 1986). Age and gender were entered as controls on the first step of all three models. The first reduced model that was built included only the parenting variables on the second step to ensure that they were related to externalizing behavior and social competence. The second reduced model built included representations of relationships on the second step of the model to ensure that it was related to social competence and externalizing behavior. Finally, a third full model was built that included all three variables on the second step to examine whether the relationship between the parenting variables and outcome variables dissipated with the inclusion of the representations of family relationships variable.

Overall, no mediation was found in any of the models. In the model predicting teacher reports of social competence, there was no relation between parenting and social competence in the reduced model, which precluded any possibility of mediation. In the model predicting parental reports of social competence, the possibility of mediation existed, since both representations of relationships and warm parenting predicted social competence in the reduced models. However, in the full model, the relation between parenting and social competence did not dissipate with the inclusion of representations of relationships (the b weight dropped from only .34 to .32), suggesting that representations of relationships did not mediate the relationship between parental reports of social competence and parenting.

In the models predicting teacher and parent reports of externalizing behavior, failures in the reduced models precluded the possibility of mediation. In the reduced model predicting teacher reports of externalizing behavior, the lack of relation between externalizing and parenting precluded the possibility of mediation. In addition, in the reduced model predicting parental reports of externalizing, the lack of relations between representations of relationships and reports of externalizing behavior similarly precluded any possibility of mediation.

\section{Discussion}

This study was designed to examine the links between parenting, children's perceptions of family relationships (as assessed in the doll story completion task), and children's social 
behavior. Overall, the study found somewhat consistent links between parenting and both children's prosocial and aggressive representations of relationships. Children whose parents reported using warm parenting techniques produced representations of relationships (as assessed in doll story narratives) that involved prosocial themes like empathy, affection, affiliation, and reparation. In contrast, parents who reported using harsh or cold parenting techniques with their children had children who were more likely to produce aggressive resolutions to conflictual relationship-oriented attachment stories. These findings support the idea that children are constructing representations of relationships consistent with their experiences in the family out of the interactions with caregivers. These findings are consistent with other studies (Laible \& Thompson, 2002) which support the idea that aspects of sensitive parenting relate to children's representations of relationships. However, these findings also expand the literature to suggest that the emotional climate of the home might also impact a child's construction of these representations.

These representations of relationships were also reflected in children's social behavior. Consistent with previous research, children's representations of family relationships (as assessed in the doll story narratives) were related to a child's social behavior. For both teacher and parental reports of social competence, positive representations of relationships in the Attachment Doll Story Task were related to higher levels of social competence. Consistent with other studies (Oppenheim et al., 1997; Turner, 1991), representations of relationships were also related to children's externalizing behavior (although only for the teacher report data). Children who represented fewer positive representations of relationships in their attachment doll stories were more likely to be reported by teachers as displaying externalizing behavior in school. Thus, this study also supports the idea that children draw upon these representations of relationships to guide their social interactions.

Also consistent with previous research (Coie \& Dodge, 1998; Eisenberg \& Fabes, 1998), parenting styles predicted social competence and externalizing behavior. Parents who reported using warm parenting rated their children as being more socially competent than those who did not. Likewise, parents who reported using harsh parenting techniques with children had children who were rated by teachers as having more externalizing problems in the classroom. Despite the somewhat consistent relationships between parenting and social behavior, representations of relationships did not mediate the relationship between children's social behavior and parenting, but rather seemed to have an independent effect. The reason why children's representations in the doll stories did not mediate the relations between parenting and social competence is not entirely clear and deserves attention in future research. One possible explanation for the lack of mediation is the likelihood that children's representations of relationships (as assessed in the doll stories) are strongly influenced by factors other than parenting including children's other significant relationships and individual factors (such as temperament). Second, this finding raises the possibility that parenting exerts its influence on a child's social development primarily through avenues other than cognitive representation. For example, scholars have argued that children acquire through relationships with parents either positive or negative affective orientations that generalize to others (Putallaz \& Heflin, 1990). Parents who are warm and supportive have children who acquire positive affective orientations that they generalize to peers, whereas parents who are harsh and aggressive have children who develop aggressive or negative orientations that they generalize to peers. 
Interestingly, parenting styles were unrelated to a child's ability to talk coherently about family relationships. Previous researchers (Bretherton, Ridgeway \& Cassidy, 1990) have suggested that a child's ability to talk coherently and openly in doll story completion tasks might reflect a child's attachment security (and thus ultimately should reflect parental sensitivity). However, when researchers have attempted to classify children as securely attached on the basis of narrative coherence (and emotional openness) in doll story completion tasks, relations with other attachment measures have been weak and not particularly consistent (e.g., Bretherton et al., 1990; Oppenheim, 1997). Thus, a child's ability to produce coherent narratives may be shaped by other factors in addition to attachment security (such as gender or verbal intelligence). In addition, however, it is possible that this study failed to find links between parenting and coherence because of the fact that parenting measures in this study assessed warmth, rather than sensitivity, which are separate, albeit related, constructs. Attachment theorists have argued that the links between coherence and parenting should be found mostly with regard to attachment-related constructs, such as sensitivity (Bretherton et al., 1988).

Furthermore, the only variable that was related to narrative coherence in this study was gender. Girls typically produced more coherent narratives than did boys and this finding is consistent with previous research (Laible \& Thompson, 2002; Openheim et al., 1997). The reason for the relation between gender and narrative coherence is not entirely clear. It may be that girls are socialized more than boys to share narratives (particularly with dolls). Also, others have found relations between gender and verbal fluency with children of this age (Laible \& Thompson, 2002), and the verbal sophistication of girls may account for their ability to tell more coherent narratives than boys.

Overall, the relations in this study among children's narrative doll story themes, parenting, and social behavior add further support to the idea that such semi-projective doll story completion tasks may tap children's representations of family relationships in a meaningful way. There is growing evidence that children's responses to these narrative measures are based on their real-life experiences within families and that they reflect children's scripted social understanding (Oppenheim et al., 1997; Warren et al., 1996). The links between both parenting and children's doll story themes and children's social behavior and the doll story themes found in this study support this idea. Of course, as others have argued (e.g. Oppenheim et al., 1997), children's responses to these relationship-oriented doll story stems likely also reflect a child's ability to regulate emotion. Each of the attachment doll story stems contained an emotionally complex, relationship-oriented story in which the child had to actively address an emotional issue. To successfully resolve each dilemma (in a prosocial manner), children must preserve their emotional organization while they tackle each emotional challenge portrayed in each doll story stem (Oppenheim et al., 1997).

Regardless, the use of doll story stems to assess aspects of children's socioemotional development deserves further attention by both researchers and clinicians. Longitudinal research linking aspects of parenting to children's representations of relationships in these narrative measures is definitely needed. Most of the work up to this point (including the current study) has linked children's themes in these doll stories with concurrent assessments of parenting, attachment, and a child's social behavior (for an exception, see Laible $\&$ Thompson, 2002). Thus, the direction of effects is not entirely clear. For example, a plausible argument could be made that children who articulate prosocial themes in representational narrative measures evoke warm parenting techniques. As others have specu- 
lated (e.g., Bell, 1968), it seems likely that the direction of the effects is bidirectional and this possibility deserves more attention by researchers. In addition, it is important to realize that our data on parenting were self-report and it is not clear how reflective these data were of parents' actual parenting practices or children's perceptions of parenting. Thus, future research also needs to examine how children's perceptions of parenting relate to their representations of relationships. Finally, researchers have only begun to explore the potential of such narrative measures for clinical use (see, e.g., Toth et al., 1997; Warran et al., 1996). The work done with maltreated children suggests that doll story completion tasks may be useful as well in exploring dysfunctional representations of relationships.

\section{References}

Baron, R. \& Kenny, D. (1986). The moderator-mediator variable distinction in social psychological research: Conceptual, strategic, and statistical considerations. Journal of Personality and Social Psychology, 51, 1173-1182.

Bell, R. Q. (1968). A reinterpretation of the direction of effects in studies of socialization. Psychological Review, 75, 81-95.

Bowlby, J. (1980). Attachment and Loss, Vol. 3, Loss: sadness and depression. New York: Basic Books.

Bretherton, I. (1990). Open communication and internal working models: Their role in the development of attachment relations. In R. A. Thompson (Ed.), Socioemotional development. Nebraska Symposium on Motivation, Vol. 36 (pp. 57-113). Lincoln, NE: University of Nebraska Press.

Bretherton, I. (1993). From dialogue to internal working models: The co-construction of self in relationships. In C. A. Nelson (Ed.), Memory and affect in development. The Minnesota Symposia on Child Psychology, Vol. 26 (pp. 237-263). Hillsdale, NJ: Lawrence Erlbaum Associates.

Bretherton, I., Prentiss, C. \& Ridgeway, D. (1990). Family relationships as represented in a story-completion task at thirty-seven and fifty-four months of age. New Directions for Child Development, 48, 85-105.

Bretherton, I., Ridgeway, D. \& Cassidy, J. (1990). Assessing internal working models of the attachment relationship: An attachment doll story completion task for 3-year-olds. In M. Greenberg, D. Cicchetti \& E. Cummings (Eds.), Attachment in the preschool years (pp. 273308). Chicago: Chicago University Press.

Cassidy, J. (1998). Child mother attachment and self in six-year-olds. Child Development, 59, $121-134$.

Coie, J. \& Dodge, K. (1998). Aggression and antisocial development. In W. Damon (Ed.), Handbook of Child Psychology (5th edn), Vol. 3, Social, emotional, and personality development (N. Eisenberg, Vol. Ed.). New York: Wiley.

Dumas, J. Martinez, A. \& LaFreniere, P. (1998). The Spanish version of the Social Competence and Behavior Evaluation (SCBE)-Preschool Edition: Translation and field testing. Hispanic Journal of Behavioral Sciences, 20, 255-269.

Eisenberg, N. \& Fabes, R. (1998). Prosocial development. In W. Damon (Ed.), Handbook of Child Psychology (5th edition), Vol. 3. Social, emotional, and personality development (N. Eisenberg, Vol. Ed.). New York: Wiley.

George, C. \& Solomon, J. (1994). Six year olds' attachment doll play procedures and classification system. Unpublished manuscript, Mills College, Oakland, CA.

Glaser, B., Horne, A. \& Myers, L. (1995). A cross-validation of the Parent Perception Inventory. Child and Family Behavior Therapy, 17, 21-34. 
Goldwyn, R., Stanley, C., Smith, V. \& Green, J. (2000). The Manchester Child Attachment Story Task: Relationships with parental AAI, SAT, and child behaviour. Attachment and Human Development, 2, 71-84.

Green, J., Stanley, C., Smith, V. \& Golwyn, R. (2000). A new method of evaluating attachment representations in young school-aged children: The Manchester Child Attachment Story Task (MCAST). Attachment and Human Development, 2, 48-70.

Hazzard, A., Christensen, A. \& Margolin, G. (1983). Children's perception of parental behaviors. Journal of Abnormal Child Psychology, 2, 49-60.

Hilton, J. \& Devall, E. (1998). Comparison of parenting and children's behavior in single-mother, single-father, and intact families. Journal of Divorce and Remarriage, 29, 23-54.

Hudson, J. (1993). Understanding events: The development of script knowledge. In M. Bennet (Ed.), The child as psychologist: An introduction to the development of social cognition. New York: Harvester Wheatsheaf.

Kaplan, N. (1987). Individual differences in six-year-olds thoughts about separation: Predicted from attachment to mother at one year of age. Unpublished doctoral dissertation, University of California-Berkley.

Kerns, K. (1994). A longitudinal examination of links between mother-child attachment and children's friendships in early childhood. Journal of Social and Personal Relationships, 11, 379-381.

LaFreniere, P. (1995). Social behavior competence and behavioral evaluation. Los Angeles: Western Psychological Services.

LaFreniere, P. \& Dumas, J. (1996). Social competence and behavior evaluation in children ages 3 to 6 years: The short form (SCBE-30). Psychological Assessment, 8, 369-377.

Laible, D. \& Thompson, R. (2002). Early parent-child conflict: Lessons in emotion, morality, and relationships, Child Development, 73, 1187-1203.

Leve, L. \& Fagot, B. (1997). Gender role socialization and discipline processes in one- and twoparent families. Sex Roles, 36, 1-21.

Maccoby, E. \& Martin, J. (1983). Socialization in the context of the family: Parent-child interaction. In E. Heatherington (Ed.), Mussen manual of child psychology (Vol. 4, 4th edn, pp. 1-102). New York: Wiley.

McCloskey, L., Figueredo, A. \& Koss, M. (1995). The effects of systemic family violence on children's mental health. Child Development, 66, 1239-1261.

Nelson, K. (1981). Social cognition in script framework. In J. Flavell and L. Ross (Eds.), Social Cognitive Development: Frontiers and possible futures (pp. 97-118). New York: Cambridge University Press.

Oppenheim, D. (1997). The attachment doll-play interview for preschoolers. International Journal of Behavioral Development, 20, 681-697.

Oppenheim, D., Emde, R. \& Warren, S. (1997). Children's narrative representations of mothers: Their development and associations with child and mother adaptation. Child Development, 68, 127-138.

Oppenheim, D., Emde, R. \& Wamboldt, F. (1996). Associations between 3-year-olds' narrative co-constructions with mothers and fathers and their story completions about affective themes. Early Development and Parenting, 78, 149-160.

Oppenheim, D., Emde, R., Hasson, M. \& Warren, S. (1997). Preschoolers face moral dilemmas: A longitudinal study of acknowledging and resolving internal conflict. International Journal of Psycho-Analysis, 78, 943-957.

Oppenheim, D., Nir, A., Warren, S. \& Emde, R. (1997). Emotion regulation in mother-child narrative co-constructions: Associations with children's narratives and adaptation. Developmental Psychology, 33, 284-294.

Page, T. \& Bretherton, I. (2001). Mother- and father-child attachment themes in the story completions of preschoolers from post divorce families: Do they predict relationships with peers 
and teachers? Attachment and Human Development, 3, 1-29.

Patterson, G. (1986). Performance models for antisocial boys. American Psychologist, 41, 432 444.

Putallaz, M. \& Heflin, A. (1990). Peer group behavior and social status. In S. R. Asher \& J. D. Coie (Eds.), Peer rejection in childhood (pp. 189-216). New York: Cambridge University Press.

Robinson, J., Herot, C., Haynes, P. \& Mantz-Simmons, L. (2000). Children's story stem responses: A measure of program impact on developmental risks associated with dysfunctional parenting. Child Abuse and Neglect, 24, 99-110.

Solomon, J. \& George, C. (1999). The measurement of attachment security in infancy and childhood. In J. Cassidy \& P. Shaver (Eds.), Handbook of Attachment: Theory, research, and clinical applications (pp. 287-318). New York: Guilford Press.

Solomon, J., George, C. \& De Jong, A. (1995). Children classified as controlling at age six: Evidence of disorganized representational strategies and aggression at home and at school. Development and Psychopathology, 7, 447-463.

Sroufe, A. (1983). Infant-caregiver attachment and patterns of adaptation in preschool: The roots of maladaptation and competence. In M. Perlmutter (Ed.), Development and policy concerning children with special needs. Minnesota symposium on child psychology (Vol. 16, pp. 41-83). Hillsdale, NJ: Erlbaum.

Thompson, R. (1998). Early sociopersonality development. In W. Damon (Ed.), Handbook of Child Psychology (5th edn), Vol. 3, Social, emotional, and personality development (N. Eisenberg, Vol. Ed.) (pp. 25-104). New York: Wiley.

Toth, S., Cicchetti, D., MacFie, J. \& Emde, R. (1997). Representations of self and other in the narratives of neglected, physically abused, and sexually abused preschoolers. Developmental Psychopathology, 9, 781-796.

Turner, P. (1991). Relations between attachment, gender, and behavior with peers in preschool. Child Development, 62, 1475-1488.

Von Klitzing, K., Kelsay, K., Emde, R., Robinson, J. \& Scmitz, S. (2000). Gender specific characteristics of 5-year-olds' play narratives and associations with behavior ratings. Journal of American Academy of Child and Adolescent Academy, 1017-1025.

Wagner, B., Cohen, P. \& Brook, J. (1996). Parent/adolescent relationships: Moderators of the effects of stressful life events. Journal of Adolescent Research, 11, 347-374.

Warren, S., Oppenheim, D. \& Emde, R. (1996). Can emotions and themes in children's play predict behavior problems? Journal of American Academy of Child and Adolescent Psychiatry, 35, 1331-1337.

Weidman, K. \& Strayhorn, J. (1992). Relationships between children's prosocial behaviors and choices in story dilemmas. Journal of Psychoeducational Asssessment, 10, 330-341.

Woolgar, M. (1999). Projective doll play methodologies for preschool children. Child Psychology and Psychiatry Review, 4, 126-134. Woolgar, M. (2001). Children's play narrative responses to hypothetical dilemmas and their awareness of moral emotions. British Journal of Developmental Psychology, 19, 115-128.

\section{Acknowledgments}

The authors greatly appreciate the assistance of: Fanny Baez, Oksana Bendus, Rebecca DunlapMorton, Julie Jones, Cindy Nash, Andrea Nichols, Craig Peters, Brooke Talsma, Wen Zhao, and Ying Zurbuchen. Support for this project was provided to the first author by a NIH Pre-doctoral Research Service Award and Templeton Foundation Young Scholars Grant. Support for this project was also provided to the second author by a Layman Grant from the Office of the Research Council and the Templeton Foundation. 